\title{
Back to the clinic. Methods II. The Architecture of Clinical Research. Subject interaction, maneuvers and disease throughout time
}

\author{
Juan O. Talavera, ${ }^{1 *}$ Ivonne A. Roy-García, ${ }^{2}$ Marcela Pérez-Rodríguez, ${ }^{2}$ Lino Palacios-Cruz ${ }^{3}$ and \\ Rodolfo Rivas-Ruíz ${ }^{2}$ \\ ${ }^{1}$ Directorate of Teaching and Research, Centro Médico ABC; ${ }^{2}$ Clinical Research Training Center, Centro Médico Nacional Siglo XXI, Instituto \\ Mexicano del Seguro Social; ${ }^{3}$ Department of Clinical Epidemiology, Sub-directorate of Clinical Research, Instituto Nacional de Psiquiatría "Dr. Ramón \\ de la Fuente", Secretaría de Salud. Mexico City, Mexico
}

\begin{abstract}
Medicine is characterized by the application of the scientific method through clinical judgment, by correct interpretation and use of the clinical course and/or natural history of the disease; its best description is observed in the architecture of clinical research. Through a temporal sequence, this model explains the phenomenon of causality with three sections: baseline status, maneuver, and outcome. The baseline status assesses who the patient is, where does he come from, his general conditions, the diagnosis, stage and aggressiveness of the pathology, complications, previous therapies, socioeconomic-cultural level, habits, therapeutic indications or contraindications, and the expected evolution is anticipated. In the maneuver, risk or prognostic factors, specific or symptomatic treatment, and general measures can be evaluated. In the outcome, early and late evolution are monitored. The model also allows the causes of follow-up loss to be determined. Anticipating patient evolution by recognizing his condition, disease, and expected effect of medical decisions allows acting in advance, since waiting for the manifestations of the evolutionary process of disease results in detriment to the patient.
\end{abstract}

KEY WORDS: Clinical course. Clinical judgment. Clinical research. Causality.

\section{De vuelta a la clínica. Métodos II. Arquitectura de la investigación clínica. Interacción sujeto, maniobras y enfermedad a través del tiempo}

\section{Resumen}

La medicina se caracteriza por la aplicación del método científico a través del juicio clínico, por la correcta interpretación y el uso del curso clínico o historia natural de la enfermedad; su descripción más lograda la observamos en la arquitectura de la investigación clínica. A través de una secuencia temporal, este modelo explica el fenómeno de causalidad con tres apartados: estado basal, maniobra y desenlace. En el estado basal se evalúa quién es el paciente, de donde proviene, sus condiciones generales, el diagnóstico, el estadio y la agresividad de la patología, las complicaciones, terapias previas, nivel socioeconómico-cultural, hábitos, indicaciones o contraindicaciones terapéuticas y se prevé la evolución esperada. De la maniobra se pueden evaluar los factores de riesgo o pronóstico, tratamiento específico, sintomático y medidas generales. En el desenlace se vigila la evolución temprana y tardía. El modelo también permite determinar las causas de pérdida de seguimiento. Anticipar la evolución del paciente al reconocer su condición, enfermedad y efecto esperado de la decisiones médicas permite actuar anticipadamente, ya que esperar las manifestaciones del proceso evolutivo de la enfermedad resulta en detrimento del paciente.

PALABRAS CLAVE: Curso clínico. Juicio clínico. Investigación clínica. Causalidad.

\footnotetext{
Correspondence:

Date of reception: 03-04-2020

*Juan O. Talavera

Date of acceptance: 13-04-2020

E-mail: jotalaverap@abchospital.com

DOI: 10.24875/GMM.M20000433

Gac Med Mex. 2020;156:430-438

Contents available at PubMed license (http://creativecommons.org/licenses/by-nc-nd/4.0/).
} 


\section{Introduction}

To understand the way, you have to walk it; to make it your own, you have to go through it over and over

POPULAR SAYING

Within the natural history of a disease, we can identify different components, such as the subject, the environment, preventive maneuvers and the disease. In the case of the clinical course, it would be necessary to add the therapeutic maneuvers and sequelae, death or cure, all of them coexisting in time. This clinical phenomenon was described by Dr. Alvan R. Feinstein under the concept of architecture of clinical research, which in its model of causality includes three components in a time sequence: baseline state, maneuver and outcome. Feinstein developed his model based on a meticulous description of medical care using the scientific method, which we know as "clinical judgment" (Fig. 1). ${ }^{1-3}$

In this article, we will show the consistency of clinical practice with the clinical research architecture model and how both are reflected on a research article or protocol.

\section{Reason for consultation (baseline state): diagnostic and prognostic demarcation}

During clinical practice, the first challenge is the translation of patient-referred manifestations into an initial conceptual grouping that allows making decisions (symptomatic, syndromic or etiological diagnosis). This set of subjective (symptoms) and objective manifestations (physical signs, laboratory or imaging findings) is obtained during the preparation of the medical record through a procedure called clinical semiology. ${ }^{4}$ In addition to this initial grouping, during the preparation of the medical record, information is collected that allows understanding the person who is being dealt with. This way, patient baseline state is structured by establishing who the person is (his demographic data, previous history and habits), and the reason why he attends for consultation, ${ }^{5}$ i.e., his ailment.

Thus, in the baseline state (which is characterized by patient initial evaluation), identifying who the patient is (gender, age, origin and the community where he lives and works, his socioeconomic and cultural stratum, lifestyle, habits and hereditary background), his general conditions (physical constitution, physical condition, as well as state of mind), his diagnosis (which manifestations does he refer and how are they integrated), the stage and aggressiveness of the pathology, complications generated by said pathology, comorbidities that accompany the pathology under study (directly related or not) or that the patient already previously suffered from, as well as previous therapies due the clinical entity under study, to its complications or to comorbidity, is sought. With this medical history, the diagnostic-therapeutic procedure is decided, always considering the expected evolution of the disease and patient expectations. That is, decisions are made with knowledge about the clinical course of the disease and patient expectations.

When preparing the medical record, the characteristics described in the architectural model of research can be identified, which at baseline state include what we know as diagnostic demarcation and prognostic stratification.

In a research project, the diagnostic demarcation (Fig. 1, Table 1a), ${ }^{6}$ initially aims to promote the inclusion of a sample that allows assessing the effect of the maneuver on the initial condition and, this way, avoid an inadequate assembly. For this, it is necessary for four requirements to be met:

1. A population with moderate to high incidence of the outcome of interest. It is important bearing in mind that low incidences require large samples or very long follow-up times, which makes it difficult for a causal explanation of the maneuver to be formulated.

2. There should be a clear definition of the baseline condition, with specific criteria that establish the state of health or disease, as appropriate.

3. The population should be free of the outcome at the time of being included and there should be the likelihood for it to occur.

4. There should not be previous indication or contraindication for the maneuver to be assessed.

In turn, the prognostic demarcation (Fig. 1, Table 1b), ${ }^{7}$ aims to identify the population with the highest pre-maneuver probability of suffering the outcome and, consequently, the decision about specific therapeutic considerations; in addition, from the methodological point of view, pertinent strategies can be implemented in order to avoid an inadequate perception of the true effect of the main or principal maneuver and thus avoid susceptibility bias. These strategies include population stratification at its baseline state and multivariate adjustment during the 
MEDICAL RECORD

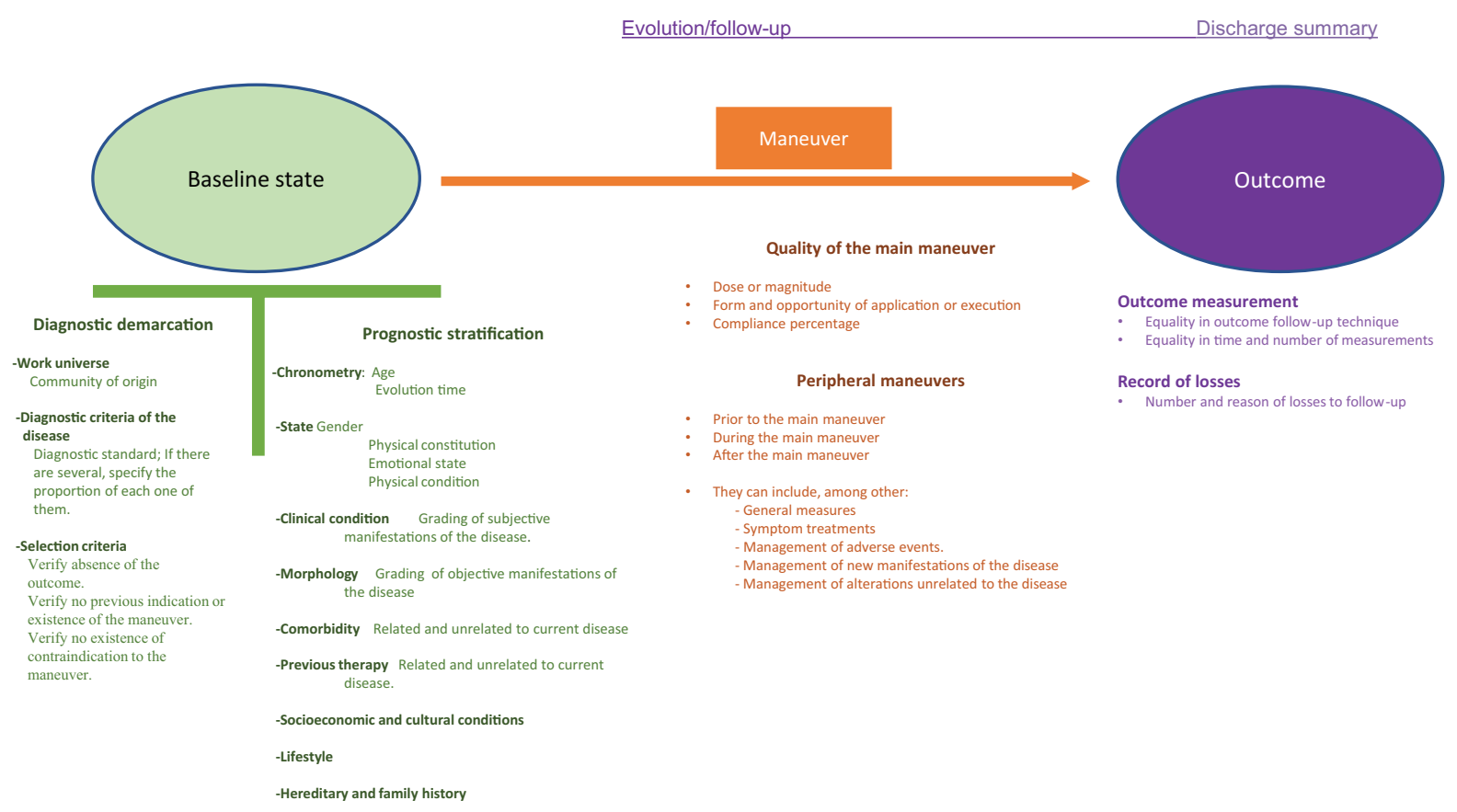

Figure 1. Clinical course of the disease (architecture of clinical research). The baseline state assesses who the patient is, where does he come from, his general conditions, the diagnosis, stage and aggressiveness of the pathology, complications, previous therapies, socioeconomic and cultural level, habits, therapeutic indications or contraindications and expected evolution. The maneuver assesses the risk factors, prognostic factors, specific treatment, symptomatic treatment and general measures. The outcome includes early and late evolution, and determines the causes of loss to follow-up. Anticipating patient evolution by recognizing his condition, disease, and the expected effect of therapeutic decisions allows acting in advance. Waiting for the manifestations of the evolutionary process of the disease results in detriment to the patient.

analysis. It should be borne in mind that this bias is not avoided with the randomization procedure that is inherent to clinical trials, not even when all characteristics are homogeneously distributed between the maneuvers.

Similarly, it should be recognized that the observed effect of the maneuver is the average effect on the predominant population; for example, if a study of patients with breast cancer admits patients with all stages of the disease, but only $5 \%$ of the population are at advanced stages, the result will be determined by the patients at early stages, even when, in theory, the selection criteria included any stage of the disease. This has been misinterpreted assuming that a maneuver is applicable to those who meet the selection criteria of the original study; however, this is not the case, actually, it only reflects the effect on the predominant population. ${ }^{8}$ Similarly, adjustment during the analysis only shows what the result is in an average population, i.e., when one or more variables are controlled or adjusted for, a multivariate statistical procedure is carried out to show the effect of the main maneuver, assuming that the rest of patient and disease characteristics are constant and that they correspond to the average of said characteristics in the study population. In both cases, the result will always be showing what occurs in the predominant population in which the study was carried out.

\section{Therapeutic decisions or identification of risk factors or prognostic indicators: main and peripheral maneuvers}

Once the patient has been characterized at baseline state, and with knowledge of the history or clinical course of the disease, a series of decisions have to be made. Initially, this implies therapeutic decisions with regard to the pathology under study; on one hand, it can be a specific treatment aimed at solving the problem, i.e., a treatment with curative intent; on the other hand, it can be a symptomatic treatment that seeks to mitigate patient discomfort; and, finally, general measures that support the 
Table 1a. Reason for consultation (baseline state): diagnostic demarcation

\begin{tabular}{|c|c|c|c|}
\hline Clinical practice & $\begin{array}{l}\text { Architectural } \\
\text { design, } \\
\text { diagnostic } \\
\text { demarcation }\end{array}$ & $\begin{array}{l}\text { Methods of } \\
\text { a research } \\
\text { article/project }\end{array}$ & $\begin{array}{l}\text { Common reasoning for } \\
\text { research and clinical practice }\end{array}$ \\
\hline $\begin{array}{l}\text { Community where the } \\
\text { patient lives }\end{array}$ & $\begin{array}{l}\text { Population } \\
\text { selection }\end{array}$ & $\begin{array}{l}\text { Work } \\
\text { universe }\end{array}$ & $\begin{array}{l}\text { It identifies a population } \\
\text { susceptible to the outcome of } \\
\text { interest; a geographic location } \\
\text { where the phenomenon is } \\
\text { common, or with moderate } \\
\text { to high prevalence of risk or } \\
\text { prognostic factors }\end{array}$ \\
\hline $\begin{array}{l}\text { Why does the } \\
\text { patient consult with } \\
\text { us. What does he } \\
\text { have and how was } \\
\text { the diagnosis made } \\
\text { (what disease does } \\
\text { he suffer from). }\end{array}$ & $\begin{array}{l}\text { Diagnosis } \\
\text { definition }\end{array}$ & $\begin{array}{l}\text { Diagnostic } \\
\text { criteria } \\
\text { specific to } \\
\text { the condition } \\
\text { under study }\end{array}$ & $\begin{array}{l}\text { It identifies the diagnosis and } \\
\text { the criteria whereby it was } \\
\text { made (e.g., type } 2 \text { diabetes } \\
\text { mellitus determined with } \\
\text { glycated hemoglobin, fasting } \\
\text { glucose or glucose-tolerance } \\
\text { test) }\end{array}$ \\
\hline
\end{tabular}

Patient condition

and disease

characteristics

that indicate or

contraindicate a

specific therapy.
It ensures the presence of subjects with the possibility of experiencing the outcome and prevents from including those who already have an indication or contraindication for any of the maneuvers

$\begin{array}{ll}\text { Selection } & \text { Selection } \\ \text { criteria* } & \text { criteria. } \\ & \text { Flowchart of } \\ & \text { patients that } \\ & \text { are finally } \\ & \text { selected }\end{array}$

\section{Example in a research article}

Day, et al. ${ }^{6}$ conducted a clinical trial to determine whether the combination of amphotericin + flucytosine or high doses of fluconazole or amphotericin improved survival in patients with cryptococcal meningitis**

The work universe were patients with human immunodeficiency virus infection diagnosed with cryptococcal meningitis who were under the care of the Tropical Diseases Hospital in Vietnam. The selected population is susceptible to experiencing the outcome, with an annual mortality higher than $60 \%$.

The diagnosis of cryptococcal meningitis was made in those who had signs and symptoms of cryptococcal meningitis and also met any of the following conditions:

1. Positive Chinese ink stain in cerebrospinal fluid.

2. Positive Cryptococcus antigen in cerebrospinal fluid.

3. Cryptococcus neoformans-positive cerebrospinal fluid culture.

4. Cryptococcus neoformans-positive blood culture (titer $>1: 10$ )

Absolute non-inclusion criteria included elevated creatinine, kidney or liver failure, pregnancy and/ or rifampicin administration, which contraindicate the assignment of the maneuver. Those subjects who already had had an indication for the maneuver before, such as a history of antifungal treatment for more than three days, which might influence the outcome, were not included.

*Selection criteria give continuity to the diagnosis of the baseline condition and define who is candidate to participate in a specific project. They can be absolute or relative. Absolute criteria are unavoidable and are related to exposure to the maneuver or to the possible occurrence of the outcome. Those related to the outcome refer to subjects who should not enter the study because the outcome already exists or because experiencing it is impossible, and those related to the maneuver refer to subjects who should not enter because there is a previous indication or contraindication for it. Relative criteria are avoidable and are generally considered to reduce the sample size, time, and resources. However, sometimes admission is not limited and these relative criteria must be considered to stratify the population by higher or lower risk of suffering the outcome (prognostic demarcation) or to make the adjustment in the analysis. ${ }^{*}$ Although clinical presentation severity (relative criterion) was not considered as an inclusion criterion, it should be considered when analyzing the results and be included in the prognostic stratification parameters.

patient to deal with the disease and therapies along with their adverse events. Of course, therapeutic decisions are added for the specific management of adverse events, complications inherent to the disease or clinical entities independent thereof, but that the patient experiences during the clinical course of the disease. In all these cases, patient prognosis should be considered and evaluated and, even when he is free of the disease, which is or are the risk factor(s) for developing it.

Identifying therapeutic decisions as actions that modify patient baseline state is usual; however, there are actions carried out by the patient or by nature that modify it as well, which we identify as risk factors when they occur before the disease or as prognostic indicators when they follow the disease (e.g., due to the action of nature [age], patient own actions [smoking], or actions due to other therapeutic indications unrelated to patient current pathology, but that anyway may have an impact on the outcome).

All these decisions or actions are referred to within the architectural model of research in the maneuvers section, which can be stratified as the main maneuver and peripheral maneuvers (Fig. 1, Table 2). The main maneuver refers to the action that represents the main interest in the research question, of which a description of a correct execution that allows measuring the quality, including the degree of adherence, should be made. In addition to this, all peripheral maneuvers should be identified, i.e., actions or condition changes that occur between the baseline state and the outcome and that can have an impact on the 
Table 1b. Reason for consultation (baseline state): prognostic demarcation

\begin{tabular}{|c|c|c|c|c|}
\hline Clinical practice & $\begin{array}{l}\text { Architectural design } \\
\text { Prognostic demarcation }\end{array}$ & $\begin{array}{l}\text { Research project/ } \\
\text { article }\end{array}$ & Reason & $\begin{array}{l}\text { Example in a research article } \\
\text { Sun et al. }{ }^{7} \text { carried out a study } \\
\text { with the purpose to evaluate } \\
\text { the association between the } \\
\text { level of vitamin D intake and the } \\
\text { development of cardiovascular } \\
\text { disease* }\end{array}$ \\
\hline $\begin{array}{l}\text { - Who is the patient (gender, } \\
\text { age, socioeconomic and } \\
\text { cultural stratus, lifestyle and } \\
\text { habits). } \\
\text { - Patient general conditions } \\
\text { (physical constitution, physical } \\
\text { condition, state of mind) } \\
\text { - Stage and aggressiveness of } \\
\text { the pathology. } \\
\text { - Complications generated by } \\
\text { the pathology. } \\
\text { - Comorbidity that accompanies } \\
\text { the pathology or previously } \\
\text { present in the patient. } \\
\text { - Previous treatments due to the } \\
\text { pathology under study or to } \\
\text { previous comorbidity. }\end{array}$ & $\begin{array}{l}\text { Stratification: } \\
\text { - Demographics. } \\
\text { - Chronometry. } \\
\text { - State. } \\
\text { - Clinical condition. } \\
\text { - Morphology. } \\
\text { - Complications. } \\
\text { - Comorbidities. } \\
\text { - Previous treatments. } \\
\text { - Socioeconomic and } \\
\text { cultural level. } \\
\text { - Lifestyle and habits. } \\
\text { - Hereditary-family history. }\end{array}$ & $\begin{array}{l}\text { Operational } \\
\text { and conceptual } \\
\text { description of } \\
\text { the confounding } \\
\text { or modifying } \\
\text { variables present } \\
\text { at baseline state }\end{array}$ & $\begin{array}{l}\text { To control the } \\
\text { effect of variables } \\
\text { other than the } \\
\text { main one or } \\
\text { already present } \\
\text { at baseline state, } \\
\text { so that their real } \\
\text { effect can be } \\
\text { isolated. }\end{array}$ & $\begin{array}{l}\text { When baseline state } \\
\text { characteristics are evaluated, the } \\
\text { following elements of prognostic } \\
\text { stratification are identified: } \\
\text { - Demographics: gender, place of } \\
\text { residence with sun exposure. } \\
\text { - Chronometry: age. } \\
\text { - State: nutritional status, body } \\
\text { mass index. } \\
\text { - Clinical and morphological } \\
\text { stratification: subjects were } \\
\text { healthy. } \\
\text { - Previous treatment: use of aspirin } \\
\text { or multivitamin treatment. } \\
\text { - Comorbidity: history of diabetes, } \\
\text { hypertension and dyslipidemia. } \\
\text { - Lifestyle and habits: smoking, } \\
\text { alcoholism, total caloric intake } \\
\text { and physical activity. } \\
\text { - Stratification by inheritance: } \\
\text { family history of cardiovascular } \\
\text { disease. }\end{array}$ \\
\hline
\end{tabular}

*When the baseline state characteristics are analyzed according to the maneuver, it is possible to identify that those patients with higher vitamin D intake had a better lifestyle (they showed a lower prevalence of smoking, had lower alcohol intake and performed more physical activity). To avoid a prognostic susceptibility bias, it is necessary to identify those baseline state conditions that contribute to a higher pre-maneuver probability of experiencing the outcome, and when conducting the statistical analysis, it is necessary to adjust for these baseline state confounding or modifying variables, so that the real effect of the main maneuver can be isolated.

latter. Taking care of both these characteristics allows avoiding or measuring the magnitude of execution bias, and pointing out the differences generated by different levels of quality between the maneuvers to be compared or by unequal use of additional maneuvers between groups. ${ }^{3}$ In this regard, it is concerning that numerous clinical trials attribute the outcome solely to the main maneuver, even in cases with a 10-year distance between the maneuver and the outcome, ignoring the series of peripheral maneuvers. ${ }^{9,10}$

\section{Patient evolution: outcome}

Every patient who undergoes therapeutic maneuvers should have repeated evaluations during follow-up in order to allow the measurement of initial response (generally an intermediate regulator), final response (outcome) and patient safety (prediction and measurement of adverse events). During follow-up, every time a patient fails to attend his assessment visits, there is concern about his health status, whether the problem has already been solved or if it has worsened and thereby he stopped attending, or if he simply forgot or decided to search medical care elsewhere; in these cases, a phone call can help identify the cause. All these measurements are considered in the architectural model outcome section, under the concept of outcome and adverse events ideal standardized measurement and loss to follow-up registration.

The ideal standardized outcome measurement implies for the assessment of all patients to be carried out under the same criteria, preferably using those internationally accepted, and at the same time of follow-up in order to prevent differential evaluation from affecting the result and generating what we know as detection bias (Fig. 1, Table 3a). ${ }^{11,12}$ Adverse events identification is always essential; there is practically no action with only benefits, and thus it will always be necessary to consider the adverse impact of the action, and even diminish the value of the benefit when the adverse event is equivalent or of higher clinical relevance. ${ }^{13}$ 
Table 2. Therapeutic decisions or identification of risk factors or prognostic indicators: main and peripheral maneuvers

$\begin{array}{lll}\text { Clinical practice Architectural design } & \begin{array}{l}\text { Research project/ Reason } \\ \text { article }\end{array}\end{array}$

\begin{abstract}
Example in a research article:
Aggarwal et al. ${ }^{10}$ published a randomized, single-blind clinical trial, the purpose of which was to assess the efficacy, safety and tolerability of metformin XR $2000 \mathrm{mg}$ once daily vs. metformin IR twice daily in patients with T2DM naïve to pharmacological treatment**
\end{abstract}

Specific treatment.

Rpecific treatment.
Risk/prognostic factor

Symptomatic treatment and general measures, as well as all those other maneuvers to treat adverse events and complications that occur during the course of the disease, whether or not related to it, or any event occurring during the follow-up period and that may impact on patient evolution
The maneuver can be a treatment, but also a risk or prognostic factor. * The quality of the main maneuver is assessed (intensity, frequency, continuity [adherence], form of application)

\section{Peripheral maneuvers.} Any event that occurs around or accompanying the main maneuver, and that may influence the outcome
Maneuver of interest, also known as main variable or independent variable

Confounding variables (related to the outcome and main maneuver) or modifying variables (related only to the outcome). These continue to be independent variables
It offers parameters that measure exposure to the main maneuver; quality of the maneuver

The participants were randomized to one of two ways to receive $2000 \mathrm{mg}$ of metformin:

1) $2000 \mathrm{mg}$ of metformin $X R$ once daily with evening meals.

2) $1000 \mathrm{mg}$ of metformin IR twice daily, in the morning and in the evening along with the meals. Both treatments for 24 weeks

Accompanying the main maneuver, there is a series of actions that can equally influence on the outcome and confound the effect of the main maneuver. Consequently, they must be considered in order to isolate the real effect of the main maneuver
In addition to drug treatment, the participants, received counseling on lifestyle and diet

*Maneuver, action that is expected to modify the baseline condition: a) Experimental, maneuver assigned for research purposes. b) Observational, maneuver present for reasons other than the research (e.g., due to the action of nature [age], self-selected [smoking], due to other indications [medical care]). Identifying the quality of the maneuver allows the performance of the intent-to-treat (ITT) analysis and the per protocol (PP) analysis. The greater the adherence, the higher the probability of seeing the real effect of the maneuver. It should be borne in mind that the ITT analysis refers to the analysis of all patients in the assigned group, whether or not they adequately received the maneuver. PP analysis refers to the analysis only of those patients whose maneuver was properly executed.

${ }_{* \star}^{*}$ Even when both groups are receiving the same dose of the drug and are adjusted for multiple interactions and glycated hemoglobin baseline values, diet and other lifestyle variables that have been shown to have a relevant effect on glycemic control in patients with type 2 diabetes mellitus are not taken into consideration during the multivariate analysis.

Similarly, in the measurement of the outcome, the number and the reason for patients that are lost to follow-up should be considered. Losses that are not due to chance, but to reasons related to the treatment and the disease are associated with the presence of transfer bias, which is common in studies whose population selection is discordant with the baseline state -case-control and cross-sectional survey studies, and case series that frequently are confused with supposed cohorts-, because when the study begins, only survivors are available, and there is no way to measure the error magnitude; the larger the number of patients lost to follow-up, the greater the likelihood and magnitude of error. In studies where patient selection coincides with the assembly, such as clinical trials and cohort studies, measuring the magnitude of error is possible given that the losses and the moment they occurred at are known (Fig. 1, Table 3b). ${ }^{14,15}$

\section{Times in the natural history or clinical course of the disease: schedule of activities}

Knowledge of the natural history and clinical course of the disease offers an estimate of patient expected evolution (Fig. 2). Based on this knowledge, different decisions, both diagnostic and therapeutic, are made in advance, anticipating possible patient evolution; the physician does not wait for an event to progress, at which point actions may be less beneficial. Knowledge of the clinical course within a research project or published article is reflected on the schedule of activities, 


\begin{tabular}{ll|l|l} 
Clinical practice Architectural design & $\begin{array}{l}\text { Research } \\
\text { project/article }\end{array}$ & Reason
\end{tabular}

\section{Standardized}

patient follow-up according

to disease

clinical course

(assessment

of intermediate

outcomes and

occurrence or

not of the primary

and sometimes

secondary

outcomes). These

evaluations

allow modifying

the therapy if

necessary

\section{Warning signs} that may indicate risk to patient life or the need to adjust the therapy are monitored

\section{It involves the} measurement of the primary outcome with equal evaluations and with the diagnostic standard, preferably blinded evaluations
It involves the variable. secondary

Adverse events*

that are related to the treatment, to the underlying disease, and even those unrelated to them, are always measured. This is a safety measure aimed at protecting the patient from any eventuality, expected or not, which represents a risk to life. This measure is methodologically required on order to weigh the real benefit of the main maneuver measurement of the primary outcome, or dependent Measurement of other outcomes can also be considered, but these measurements will always be exploratory

Defining the outcome as accurately as possible and at specific time points is required. Inappropriate and out-of-time measurement can lead to under- or overdiagnosis and generate between-group artificial differences. The greater the number of visits in any of the groups, the higher the probability of detecting the outcome, thus generating biases (the higher number of visits can be generated by a larger number of adverse events, dose adjustment or diagnostic suspicion, among others)

Adverse events

Monitoring and measurement of adverse events or complications yield warning signs that allow improving patient care and that force to diminish the benefit of the main maneuver when these events put patient life at risk, or when harm exceeds the expected benefit

\section{Example in a research article}

In 2004, March et al. ${ }^{11}$ published a clinical trial called "Treatment for Adolescents with Depression Study (TADS)", which had the purpose to evaluate the effectiveness of four treatment modalities for children and adolescents with major depressive disorder*

The primary and secondary outcomes evaluated the improvement in symptoms of depression and suicidal ideation using the following scales:

- Children's Depression Rating Scale

Revised (CDRS)

- Clinical Global Impressions (CGI)

- Reynolds Adolescent Depression

Scale (RADS), a self-report instrument.

- Suicidal Ideation Questionnaire-Junior

High School Version (SIQ-Jr).

Outcome evaluations were carried out at six and 12 weeks for each of the treatment groups

Among the evaluated adverse events, presence of mania, hypomania, irritability, agitation, anxiety, fatigue, sedation, suicidal behavior and self-harm was found

*Although suicidal behavior and self-harm were present in a certain percentage of patients since the beginning of the study, and their reduction was measured as a secondary outcome, the possibility of their occurrence should also be considered, and it is therefore difficult to distinguish whether they are part of the natural history of the disease or of the clinical course when antidepressant treatment is started; sometimes, they can be considered as adverse events, and if so, a clear reduction is observed with the treatment. Among other aspects, outcome measurement was at six and 12 weeks, which is consistent with the time required to observe a response in children and adolescents, as opposed to adults, in whom it occurs earlier.

which allows planning and recording the time sequence at which the different components of the phenomenon of causality occur.

\section{Final comment}

We can conclude by highlighting that the information contained in research articles reflects clinical practice; their reading offers us a journey through the natural history or clinical course of a disease. The application of the architectural model of research on critically reading these texts allows examining the phenomenon of causality at its different components, identifying the temporality they appear with, the contribution of each one of them, and recognizing those in which modifications are feasible. Conscious reflection of this knowledge each time patient ailments are dealt with allows making objective decisions; anticipating patient evolution by recognizing his condition, his disease, and the consequences of diagnostic-therapeutic decisions allows acting in advance and reduce patient harm. Waiting to respond until different events occur will result in detriment to patient health. 
Table 3b. Patient evolution: loss to follow-up

Clinical practice

Architectural design

Every time a patient

is lost to follow-up,

the possibility for this

to indicate treatment

failure, complication

or adverse event

should be considered.

Although it can also be

due to resolution of the problem, or search for care elsewhere

Loss to follow-up. groups
Research project/ Reason

article

Identifying the cause allows estimating the possibility of having an inclination in the result in favor of any of the
Flow chart of patients lost to follow-up. Usually it is integrated to the initial diagram that accompanies patient selection
Documenting the losses is essential in order to identify the true success of medical actions and to avoid overestimating or underestimating the result thereof

\section{Example in a research article}

Miguel et al., in 2018, ${ }^{14}$ published the results of a study that had the purpose to assess the effectiveness of a treatment algorithm for bipolar disorder (BPD), using the treatment alternatives available in the Brazilian health system*

The study initially included 107 patients. At week 8 of follow-up, only 88 participants attended and at week 16 , only 84 participants did, which represented a follow-up loss of $21 \%$ of total participants. The causes of follow-up loss included patient dropout and the occurrence of treatment-related adverse events.

*It is common to find in articles only data of those patients who remained until the end of the study; in fact, many articles do not mention what the initial size of the population was. In this work, the original sample was 107 patients, out of whom only 84 remained up to week 16. Each table of the analysis of the clinical course/natural history of the disease should show total number of patients existing up to that moment. Comparisons should be made to show whether patients who are lost after their last measurements are similar to those who continue, which would allow estimating the magnitude of the transfer bias.

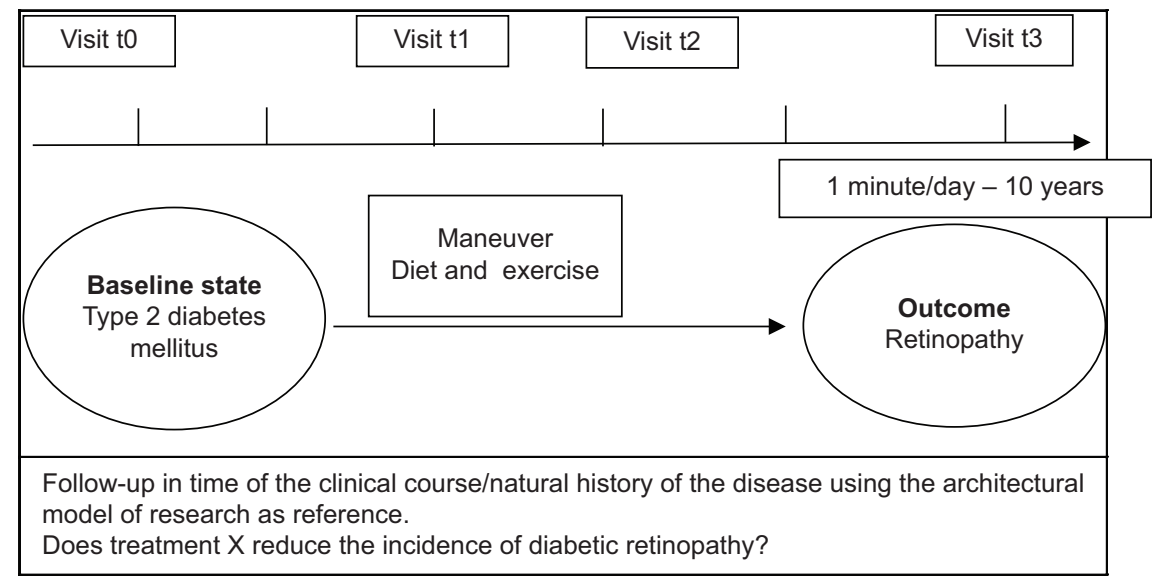

\begin{tabular}{|c|c|c|c|c|c|c|c|c|}
\hline $\begin{array}{l}\text { Characteristic to be } \\
\text { recorded }\end{array}$ & $\begin{array}{l}\text { to Visit } 1 \\
\text { Month } 0\end{array}$ & $\begin{array}{l}\text { to Visit } 2 \\
\text { Month } 1\end{array}$ & $\begin{array}{l}\text { t1 Visit } 3 \\
\text { Month } 3\end{array}$ & $\begin{array}{l}\text { t1 Visit } 4 \\
\text { Month } 6\end{array}$ & $\begin{array}{c}\text { t1, t2, t3 Visit } 5 \\
\text { Month } 12\end{array}$ & $\begin{array}{l}\text { t1 Visit } 6 \\
\text { Month } 18\end{array}$ & $\begin{array}{c}\text { t1, t2, t3 Visit } 7 \\
\text { Month } 24\end{array}$ & $\begin{array}{l}\text { t1, t2, t3 Visit } 8 \\
\text { Month } 36\end{array}$ \\
\hline
\end{tabular}

\begin{tabular}{|c|c|c|c|c|c|c|c|c|}
\hline Age & $x$ & - & - & - & - & - & - & - \\
\hline Gender & $x$ & - & - & - & - & - & - & 一 \\
\hline Evolution time & $x$ & - & - & - & - & - & - & - \\
\hline Body mass index & $x$ & $x$ & $x$ & $x$ & $x$ & $x$ & $x$ & $x$ \\
\hline Glucose & $x$ & - & - & $x$ & $x$ & $x$ & $x$ & $x$ \\
\hline Diet and exercise & $x$ & $x$ & $x$ & $x$ & $x$ & $x$ & $x$ & $x$ \\
\hline Visual disturbances & - & - & - & - & $x$ & - & $x$ & $x$ \\
\hline Diabetic retinopathy & $x$ & - & - & - & $x$ & - & $x$ & $x$ \\
\hline
\end{tabular}

Figure 2. Schedule of activities (according to the architecture of clinical research). Visits $t 0, t 1, t 2$ and $t 3$ are related to the architectural model; t0 $=$ baseline state; $t 1,=$ maneuver; $t 2=$ early response to the maneuver and possible eventualities, $t 3=$ outcome. Measurements at time-points 1,2 and 3 can overlap during follow-up and be performed multiple times $1.1,2.1,3.1,1.2,2.2,3.2 \ldots$ 
Every time we read an article or design and execute a research project, we are recreating the phenomenon of causality we live day by day with in clinical practice. Integrating research understanding and activities into our medical practice increases our experience to understand this phenomenon and shortens the time to become an expert in any given area. We should not miss the opportunity of learning from others' experience; by relying only on our experience, it will take us many years before we can act in the best possible way. Although we will never completely master the clinical subject of our interest (e.g., type 2 diabetes mellitus, epilepsy, multiple sclerosis, etc.), we will shorten the path to mastering the subject by adding structured reading, understanding and participation in the research process to our clinical work.

Finally, we must get back to Dr. Alvan R. Feinstein's expression, who refers that, in the architectural model, there is nothing a sensible doctor does not know or cannot understand. ${ }^{16}$ To understand the way, you have to walk it; to make it your own, you have go through it over and over again.

\section{Conflict of interests}

The authors declare that they have no conflicts of interest.

\section{Funding}

The authors did not receive any sponsoring to carry out this article.

\section{Ethical disclosures}

Protection of human and animal subjects. The authors declare that no experiments were performed on humans or animals for this research.
Confidentiality of data. The authors declare that no patient data appear in this article.

Right to privacy and informed consent. The authors declare that no patient data appear in this article.

\section{References}

1. Feinstein AR. Clinical Epidemiology: the architecture of clinical research. USA: Saunders; 1985

2. De la Sierra T. El Método Científico Aplicado a la Clínica. Mexico: Méndez Editores. 2011

3. Talavera JO, Wacher-Rodarte NH, Rivas-Ruiz R. Investigación clínica III. Estudios de causalidad. Rev Med Inst Mex Seguro Soc. 2011;49:289-94.

4. Casademont J. Fisiopatología y semiología clínica. ¿Dónde estamos y hacia dónde deberíamos dirigirnos? Educ Med. 2018;19:48-50.

5. Feinstein AR. Boolean algebra and clinical taxonomy. I. Analytic synthesis of the general spectrum of a human disease. N Engl J Med. 1963; 269:929-938.

6. Day JN, Chau TT, Wolbers M, Mai PP, Dung NT, Mai NH, et al. Combination antifungal therapy for cryptococcal meningitis. $N$ Engl $\mathrm{J}$ Med. 2013;368:1291-302.

7. Sun Q, Shi L, Rimm EB, Giovannucci EL, Hu FB, Manson JE, et al. Vitamin $D$ intake and risk of cardiovascular disease in US men and women. Am J Clin Nutr. 2011;94:534-542.

8. Hurvitz SA, Martin M, Symmans WF, Jung KH, Huang CS, Thompson AM, et al. Neoadjuvant trastuzumab, pertuzumab, and chemotherapy versus trastuzumab emtansine plus pertuzumab in patients with HER2-positive breast cancer (KRISTINE): a randomised, open-label, multicentre, phase 3 trial. Lancet Oncol. 2018;19:115-126.

9. Holman RR, Paul SK, Bethel MA, Matthews DR, Neil HA. 10-year follow-up of intensive glucose control in type 2 diabetes. N Engl J Med. 2008:359:1577-1589.

10. Aggarwal N, Singla A, Mathieu C, Montanya E, Pfeiffer AFH, Johnsson E, Zhao J, lqbal N, Bailey C. Metformin extended-release versus immediate-release: an international, randomized, double-blind, head-to-head trial in pharmacotherapy-naïve patients with type 2 diabetes. Diabetes Obes Metab. 2018;20:463-467.

11. March J, Silva S, Petrycki S, Curry J, Wells K, Fairbank J, et al. Fluoxetine, cognitive-behavioral therapy, and their combination for adolescents with depression: Treatment for Adolescents with Depression Study (TADS) randomized controlled trial. JAMA. 2004;292:807-820.

12. Treatment for Adolescents with Depression Study Team. Treatment for Adolescents with Depression Study (TADS): rationale, design, and methods. J Am Acad Child Adolesc Psychiatry. 2003;42:531-542.

13. The SPRINT Research Group. A randomized trial of intensive versus standard blood pressure control. N Engl J Med. 2015;373:2103-2116.

14. Miguel SR, Lima AF, Cruz LN, Cohen M, Zimmermann JJ, Ziegelmann PK, et al. Bipolar disorder mixed episodes: a pragmatic trial of a public health treatment effectiveness. Value in Health Regional Issues. 2018; 17:158-163.

15. Talavera JO, Roy-García I, Palacios-Cruz L, Rivas-Ruiz R, Hoyo I, Pérez-Rodríguez M. De vuelta a la clínica. Métodos I. Diseños de investigación. Mayor calidad de información, mayor certeza a la respuesta. Gac Med Mex. 2019;155:399-405.

16. Feinstein AR. Clinical biostatistics. V. The architecture of clinical research (concluded). Clin Pharmacol Ther. 1970;11:755-771. 